\title{
Machining and Surface Characteristics of AISI 304L After Electric Discharge Machining for Copper and Graphite Electrodes in Different Dielectric Liquids
}

\author{
Saba Anjum \\ Mechanical \\ Engineering \\ Department, University \\ of Engineering and \\ Technology Taxila, \\ Pakistan \\ sabaanjum_2k9@ \\ yahoo.com
}

\author{
Masood Shah \\ Mechanical \\ Engineering \\ Department, University \\ of Engineering and \\ Technology Taxila, \\ Pakistan \\ masood.shah@ \\ uettaxila.edu.pk
}

\author{
N. A. Anjum \\ Mechanical \\ Engineering \\ Department, University \\ of Engineering and \\ Technology Taxila, \\ Pakistan \\ nazeer.anjum@ \\ uettaxila.edu.pk
}

\author{
Shahid Mehmood \\ Mechanical \\ Engineering \\ Department, University \\ of Engineering and \\ Technology Taxila, \\ Pakistan \\ shahid.mehmood@ \\ uettaxila.edu.pk
}

\author{
Waqas Anwar \\ Institute of Space \\ Technology, \\ Engineering Research \\ and Development \\ Sector, Islamabad, \\ Pakistan \\ waqasanwar_16@ \\ yahoo.com
}

\begin{abstract}
In Electric Discharge Machining (EDM), the thermal energy used for material erosion depends on the intensity of electric sparks, the thermal conductivities of electrode material and the dielectric liquid. In this paper, the effect of EDM on AISI 304L steel is studied using copper and graphite electrodes and distilled water and kerosene oil as dielectric liquids. Material Removal Rates (MRR), Tool Wear Rates (TWR) and surface conditions are calculated for four different combinations with the two electrode materials and the two dielectric liquids. These investigations are carried out at different pulse currents. Machined surfaces are evaluated by morphological studies, energy dispersive spectrographs (EDS) and white layer thickness using Scanning Electron Microscopy (SEM). It is found that a transfer of carbon takes place from the kerosene oil and the graphite electrodes into the machined surface which alters the metallurgical characteristics, depending on the electrical and thermal conductivities of the electrode material and the dielectric liquid.
\end{abstract}

Keywords-electric discharge machine; material removal rate; electrode wear rate; white layer

\section{INTRODUCTION}

Electric Discharge Machining (EDM) is a non-conventional machining process, which is used for machining of complex and intricate shapes with high precision. This is a non-contact machining process in which material is removed by the thermal energy produced by electric sparks in a dielectric medium. A part of molten material is removed only by solidifying residue on the surface and a surface layer is produced which is known as white layer [1-3]. Electrodes used in electric discharge machining are generally made of copper, graphite, Tungsten, aluminum, brass etc. based on the electrical and thermal conductivities. Tool wear rate is the biggest problem in EDM which causes inaccurate machining [4]. Proper selection of electrode material is necessary for attaining desired surface conditions [5]. A number of researches are carried out to evaluate the effect of different type of materials, sizes and geometries for electrode $[6,7]$.

The selection of electrode material as well as the proper dielectric liquid is very important since these parameters determine the Material Removal Rate (MRR), the Electrode Wear Rate (EWR), and surface finish [8]. The increase in pulse current causes higher electrode wear. Tool Wear Rate (TWR), MRR, diametric over cut on tool steel have been investigated and it was found that aluminum and copper electrodes offer best machining rates [9]. In [10], authors studied MRR and EW of aluminum and mild steel for copper and brass electrodes and found that electrode wear was higher for machining of mild steel compared to aluminum. In [11], authors investigated the effect of copper and graphite electrode on AISI P20 Tool Steel for different polarities and determined that copper electrode provides best surface roughness for negative polarity. In [12], authors presented a detailed review for the effect of different types of dielectric liquids on EDM characteristics and concluded that with distilled water machining accuracy is superior as compared to hydrocarbon oil. In [13], authors determined the effect of using deionized water, kerosene oil and water in oil emulsion as dielectric liquid on C35 carbon steel and found that microcracks formed with water as a dielectric liquid had little penetrations as compared to the kerosene oil. The consequent residual stresses increase below the surface reaching maximum value $[14,15]$. In [16], authors studied the effect of oil based, de-ionized water, gracious and commercial water based dielectric liquids and found that water and gracious based dielectric liquids offer good MRR and are health friendly. In [17], authors compared the influence of kerosene and distilled water for electric discharge machining of Ti-6Al-4V and found that carbon from kerosene oil stuck with electrode surface and retards machining process.

Experimental investigations which are limited to the determination of the effect different electrode materials on 
material removal rate and electrode wear rate are available [4, 18]. The effect of electrode materials in combination with different types of dielectric liquids is rarely investigated. The present study is unique in such a way that surface morphology, its composition and white layer thickness are studied along with MRR and TWR for different combinations of electrode material and dielectric liquid. The effects of copper and graphite electrodes in both dielectric liquids (distilled water and kerosene oil) are investigated for EDM of carbon steel AISI 304L.

\section{EXPERIMENTATION}

The material investigated is low carbon steel AISI 304L and chemical composition of the material is presented in Table 1. The experimental work is conducted by using die sinking electrical discharge machine Neuer M 50. The effect of two types of electrode material i.e graphite and copper for two types of dielectric liquids i.e kerosene and de-ionized water are evaluated. As different kinds of dielectric liquids are used in this study, machining is carried out in such a way that one dielectric liquid could not be contaminated by the other. For this purpose, a workpiece fixture is used that contains two separate chambers as shown in Figure 1. Machining is performed in one chamber and other chamber is used as reservoir. An external pump is used to deliver dielectric liquid from reservoir to the machining chamber. The experimental conditions used for the current investigation are presented in Table II. Discharge current is the only electric parameter which is varied whereas other electric parameters such as pulse-ON time, pulse-OFF time, voltage, and gap are kept constant. Physical properties of the electrode materials are given in Table III.

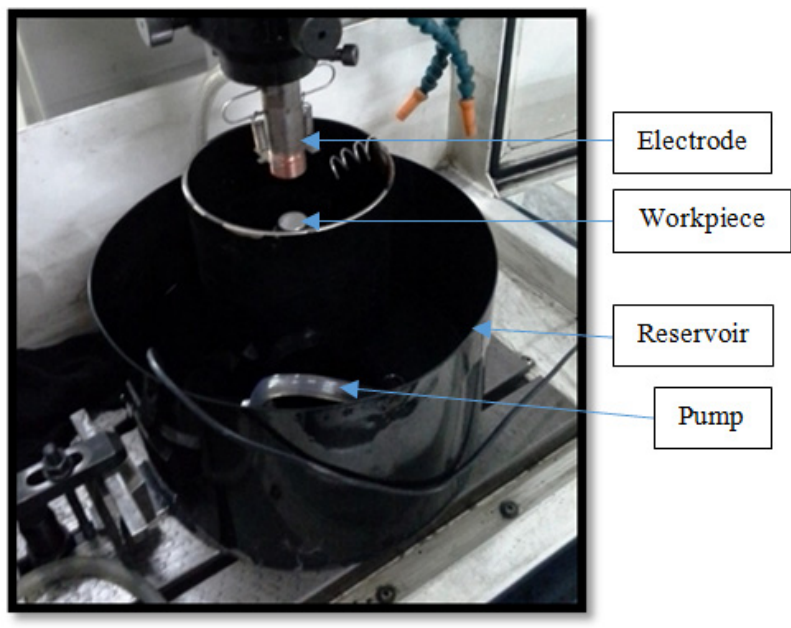

Fig. 1. Experimental setup.

TABLE I. CHEMICAL COMPOSITION OF STAINLESS STEEL GRADE 304L

\begin{tabular}{|c|c|c|c|c|c|c|c|c|}
\hline Chemical & $\mathbf{C}$ & Mn & $\mathbf{P}$ & $\mathbf{S}$ & $\mathbf{S i}$ & $\mathbf{C r}$ & $\mathbf{N i}$ & $\mathbf{N}$ \\
\hline Percentage & 0.030 & 2.00 & 0.045 & 0.030 & 0.75 & $18-$ & $8-$ & 0.10 \\
& $\max$ & $\max$ & $\max$ & $\max$ & $\max$ & 20 & 12 & $\max$ \\
\hline
\end{tabular}

TABLE II. EXPERIMENTAL CONDITIONS

\begin{tabular}{|c|c|}
\hline Working parameters & Description \\
\hline Work piece material & SS 304L \\
\hline Electrode material & Copper and graphite \\
\hline Dielectric & Water and kerosene \\
\hline Peak current & $4.5,6,9,12 \mathrm{~A}$ \\
\hline Plus duration & $90(\mu \mathrm{s})$ \\
\hline Plus off time & $5(\mu \mathrm{s})$ \\
\hline Working time & 30 minutes \\
\hline
\end{tabular}

TABLE III. PHYSICAL PROPERTIES OF COPPER AND GRAPHITE ELECTRODES [4]

\begin{tabular}{|c|c|c|}
\hline Physical Properties & Copper & Graphite \\
\hline Melting point $\left({ }^{\circ} \mathrm{C}\right)$ & 1083 & 455 \\
\hline Thermal conductivity $(\mathrm{W} / \mathrm{mK})$ & 380.7 & 160.0 \\
\hline $\begin{array}{c}\text { Electrical conductivity compared with } \\
\text { silver }(\%)\end{array}$ & 92 & 0.11 \\
\hline $\begin{array}{c}\text { Electrical resistivity }(\mu / \mathrm{cm}) \\
\text { Coefficient of thermal expansion } \\
\left(\times 10^{-6} \times \mathrm{C}^{-1}\right)\end{array}$ & 1.96 & 0.12 \\
\hline Specific gravity at $20{ }^{\circ} \mathrm{C}(\mathrm{g} / \mathrm{cm} 3)$ & 6.6 & 7.8 \\
\hline Specific heat $\left(\mathrm{cal} / \mathrm{g}{ }^{\circ} \mathrm{C}\right)$ & 0.092 & 0.17 \\
\hline
\end{tabular}

Four different combinations of electrode material and dielectric liquid during EDM which are evaluated in this study are given in Table IV. The material removal rate (MRR) and the electrode wear rate (EWR) are obtained by measuring the masses of the work-piece and the electrode before and after machining and corresponding formulas are given below,

$$
\begin{aligned}
& \operatorname{MRR}=\left(M_{1}-M_{2}\right) / \rho_{w} \cdot T \\
& \operatorname{EWR}=\left(m_{1}-m_{2}\right) / \rho_{E} . T
\end{aligned}
$$

Where $M_{1}$ and $M_{2}$ are masses of workpiece before and after machining respectively. $m_{1}$ and $m_{2}$ are masses of electrode before and after machining respectively. $\rho_{\mathrm{w}}$ is the density of workpiece material and $\rho_{\mathrm{E}}$ is the density of electrode material. $\mathrm{T}$ is machining time.

After EDM machining, the samples are cut perpendicular to machined surface, embedded in epoxy and then polished. Then etched with diluted solution of HF with Nitric acid for 15 seconds. Surface morphology and white layer thickness are determined by scanning electron microscope (SEM).

TABLE IV. COMBINATIONS OF ELECTRODE MATERIAL AND DIELECTRIC LIQUIDS

\begin{tabular}{|c|c|c|c|}
\hline Conditions & Electrode Material & Dielectric Liquid & Symbol \\
\hline 1 & Copper & Distilled water & CW \\
\hline 2 & Copper & Kerosene oil & CK \\
\hline 3 & Graphite & Distilled water & GW \\
\hline 4 & Graphite & Kerosene oil & GK \\
\hline
\end{tabular}

\section{RESULTS AND DISCUSSIONS}

\section{A. Material Removal Rate (MRR)}

Initially material removal rate (MRR) is determined for four different discharge current levels. Results of MRR are given in Table $\mathrm{V}$ and are shown in Figure 2. It is observed that distilled water when used as dielectric liquid gives higher MRR as compared to kerosene oil for both of the electrode materials. The behavior of MRR with respect to electrode material is 
different on lower and higher side of discharge current. At lower side MRR is higher for graphite, whereas at higher side copper material gives higher values. For high discharge current (roughing conditions), copper electrode is giving higher MRR whereas for lower discharge current (finishing conditions) graphite electrode is suitable. This is due to lower ionization energy is required for dielectric break-down in case of water as compared to kerosene oil. Also it can be seen that MRR is proportional to pulse current for all combination.

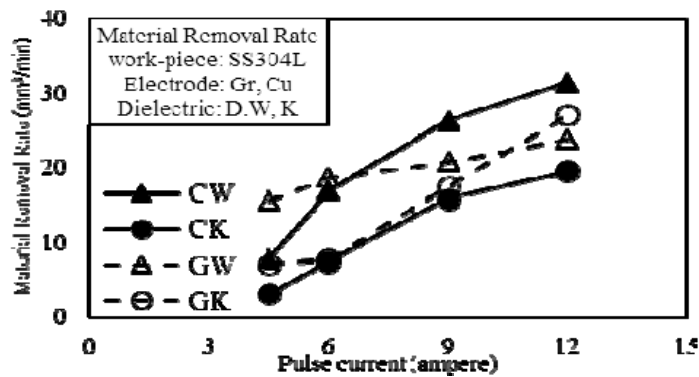

Fig. 2. Material removal rate with respect to pulse current.

TABLE V. MRR AT DIFFERENT EXPERIMENTAL CONDITIONS.

\begin{tabular}{|c|c|c|c|c|}
\hline \multirow{2}{*}{$\begin{array}{c}\text { Current } \\
(A)\end{array}$} & \multicolumn{2}{|c|}{ Copper $\left(\mathrm{mm}^{3} / \mathrm{min}\right)$} & \multicolumn{2}{c|}{ Graphite $\left(\mathrm{mm}^{3} / \mathrm{min}\right)$} \\
\cline { 2 - 5 } & Distilled water & Kerosene & Distilled water & Kerosene \\
\hline 4.5 & 7.76 & 3.08 & 15.6 & 7.12 \\
\hline 6 & 16.9 & 7.43 & 18.6 & 7.70 \\
\hline 9 & 26.2 & 15.8 & 20.7 & 17.4 \\
\hline 12 & 31.4 & 19.5 & 23.8 & 27.0 \\
\hline
\end{tabular}

\section{B. Electrode Wear Rate (EWR)}

Since machining occurs at very high temperature that increase probability of chemical reaction between the elements of electrode material and dielectric liquid, due to which erosion of electrode material can take place. Tool wear rate is usually determined for identification of dimensional accuracy of the machined geometry, also the machining cost is suffered by electrode wear. Dielectric liquids act as coolant for both workpiece and electrode after each discharge. The cooling rate depends essentially on the thermal conductivity of dielectric liquid. The results of TWR are given in Table VI and shown in Figure 3. Distilled water has lower de-ionization level relative to kerosene oil which results intense sparks comparative to kerosene oil. Also copper material produces more intensive sparks due to high electric conductivity as compared to graphite material. However relative lower thermal conductively of graphite generate more heat and hence melting. Therefore, the wear rate of graphite in combination with water is higher. However, the combination of water and copper has an abnormal behavior where electrode wear rate is decreasing with increasing discharge current. This shows that spark generation is becoming unstable with increasing discharge current. Also negative wear ratio is observed in case of kerosene oil only as carbon layer stuck at the bottom surface of electrode. The carbon is produced due to disintegration of hydrocarbon kerosene oil.
TABLE VI. TWR AT DIFFERENT EXPERIMENTAL CONDITIONS.

\begin{tabular}{|c|c|c|c|c|}
\hline \multirow{2}{*}{ Current (A) } & \multicolumn{2}{|c|}{ Copper $\left(\mathrm{mm}^{3} / \mathrm{min}\right)$} & \multicolumn{2}{c|}{ Graphite $\left(\mathrm{mm}^{3} / \mathrm{min}\right)$} \\
\cline { 2 - 5 } & Dis. water & Kerosene & Dis. water & Kerosene \\
\hline 4.5 & 0.749 & -0.3 .00 & 2.80 & -0.369 \\
\hline 6 & 0.787 & -0.150 & 3.98 & -0.723 \\
\hline 9 & 0.337 & 0.337 & 4.57 & -0.560 \\
\hline 12 & 0.0749 & 1.650 & 5.31 & 0.737 \\
\hline
\end{tabular}

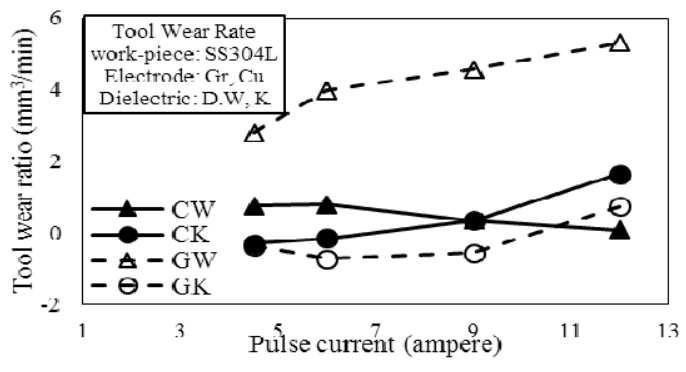

Fig. 3. Tool wear ratio with respect to pulse current

\section{Microscopy}

After each spark, a decrease in pressure occurs resulting a tiny localized explosion, due to which, molten material is splashed away forming surface crater. Only a portion of material could be removed and the remaining material resolidified forming a layer. This layer has different characteristics compared to the base material. It is also well noted by different studies that this layer is known as white layer and its thickness depends on the discharge energy [1]. The amount of discharge energy per unit area depends on Pulse current and Pulse-On time. Presence of white layer is undesirable due to its poor characteristics. This layer is harder and brittle due to rapid cooling. Due to rapid cooling residual stresses are developed, which are tensile in nature. Surface cracking occur if magnitude of residual stresses exceed material strength. In [19], these cracks were classified into three types. The first type of surface cracks initiates from the surface and penetrates into white layer up to the interface of white layer and base material. The second type of surface cracks is those which penetrate into the base material. The third type of surface cracks is found near boundaries of craters and globules. These cracks have very low penetration and do not affect the surface properties.

Surface morphology of the machined surface using kerosene oil as dielectric is shown for both electrodes in Figure 4. It is clearly shown that surface cracks are uniformly distributed on the whole surface however these cracks are more pronounced when graphite electrode is used. The crosssectional images are indicating that these cracks are of the first type that penetrate until the interface. Globules and surface pits are seen in case of copper electrode whereas blackish contents are collected in crater like cavities for graphite electrode, which are definitely carbon particles. [20] reported high increase in carbon contents on the machined surface by more cracking of kerosene oil for graphite electrode and also due to the decomposition of graphite into carbon contents in vigorous condition. 

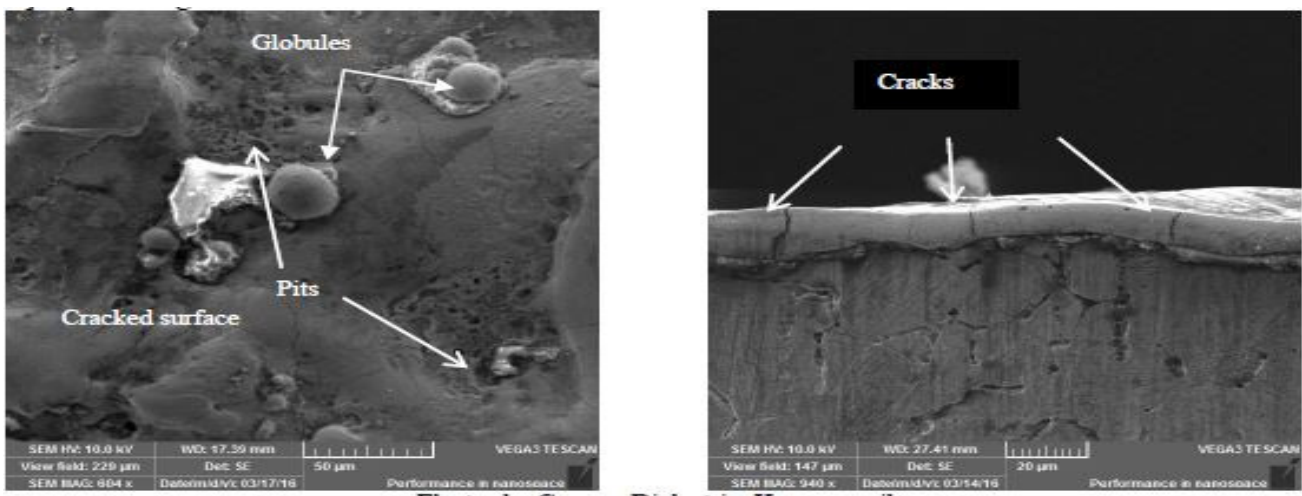

Electrode: Copper, Dielectric: Kerosene oil
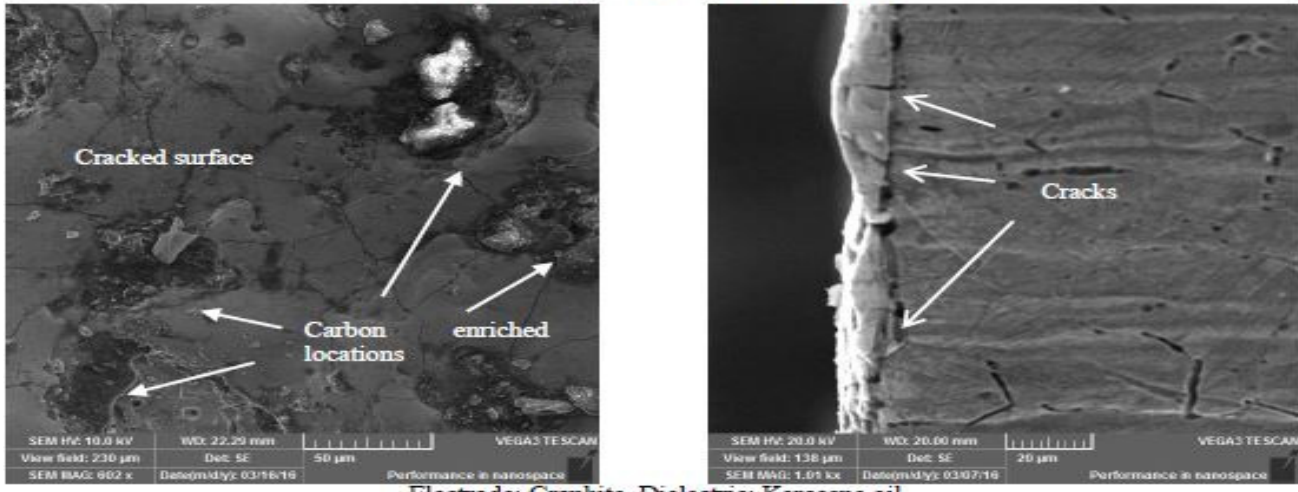

Electrode: Graphite, Dielectric: Kerosene oil

Fig. 4. Influence of copper and graphite electrode on surface morphology using kerosene oil at 6 A pulse current
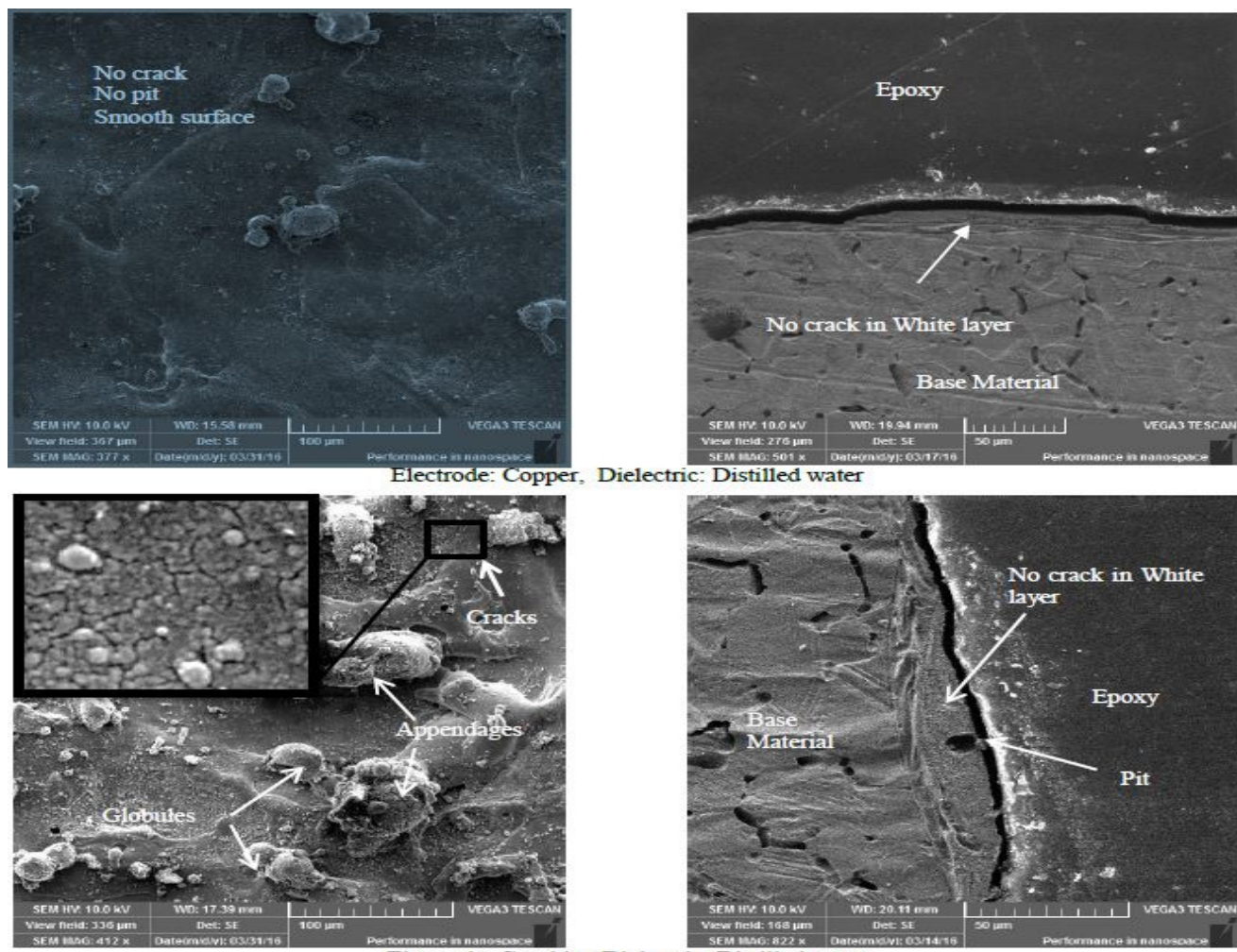

: Distilled water

Electrode: Graphite, Dielectric: Distilled water

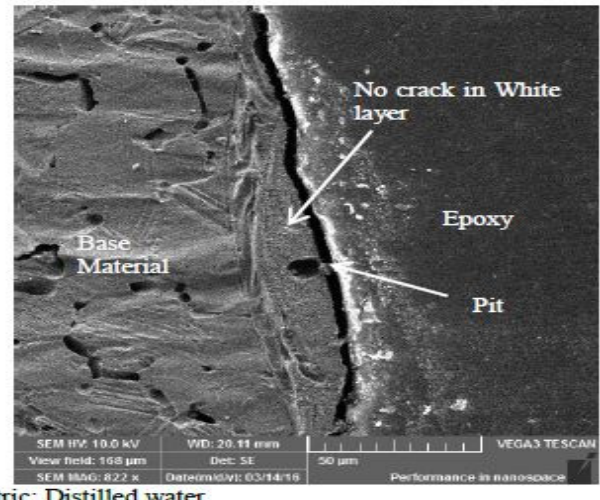

Fig. 5. Influence of copper and graphite electrodes using distilled water at $6 \mathrm{~A}$ pulse current. 
For the distilled water as the dielectric liquid, the effect of electrode materials on electric discharge machined surface is shown in Figure 5. It is observed that the use of copper electrodes is resulting to a relatively smooth surface with less amount of cavities and globules. None of the cracks are visible on the surface. The surface obtained by graphite electrode is uneven containing globules and appendages of resolidified material on crater rims. Surface seems to have cracks of the third type having very low penetration into the white layer. This might be because of relatively higher cooling rate of the molten material in distilled water. White layer displays less micro cracks for the work-piece using kerosene, compared to that using distilled water. This is due to the increase of carbon contents in the white layer that make material hard and brittle. Surface is cracked when residual stresses overcome the ultimate strength of the material. Energy Dispersive Spectrographs (EDS) of machined surface using kerosene oil and distilled water along with graphite electrode are shown in Figure 6. It is observed that the white layer is contaminated by carbon contents that are transferred by decomposition of kerosene oil and graphite electrode during machining. Therefore the white layer formed by combination of kerosene oil as dielectric liquid and graphite electrode has highest contamination of carbon.
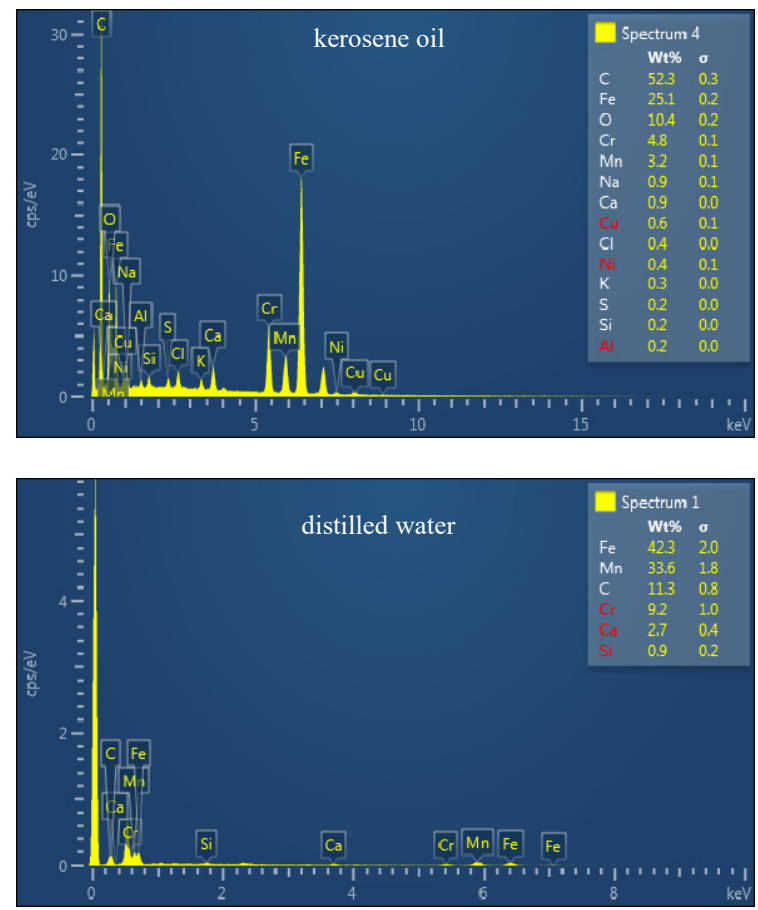

Fig. 6. EDS spectrographs for graphite electrode in kerosene oil and distilled water

TABLE VII. WHITE LAYER THICKNESS AT DIFFERENT CONDITIONS

\begin{tabular}{|c|c|c|c|c|}
\hline \multirow{2}{*}{$\begin{array}{c}\text { Current } \\
(\mathrm{A})\end{array}$} & \multicolumn{2}{|c|}{ Copper } & \multicolumn{2}{c|}{ Graphite } \\
\cline { 2 - 5 } & Dis. water & Kerosene & Dis. water & Kerosene \\
\hline 6 & 7.90 & 15.80 & 4.58 & 17.67 \\
\hline 9 & 10.16 & 6.08 & 5.51 & 21.31 \\
\hline 12 & 12.94 & 21.65 & 7.95 & 13.56 \\
\hline
\end{tabular}

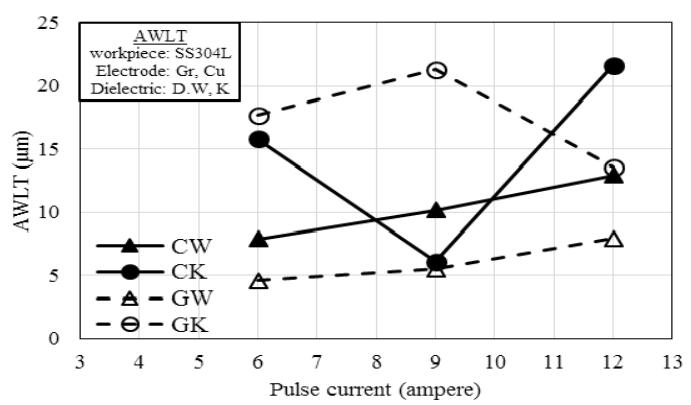

Fig. 7. AWLT for different combinations.

The average values of white layer thickness for four different conditions are given in Table VII and their behavior with pulse current are shown in Figure 7. A comparison of the white layer thickness of the two dielectric shows that the average thickness of white layer using kerosene is higher than distilled water for both electrode materials. This is because of the difference in thermal conductivities of water and kerosene. The thermal conductivity of water is more than kerosene, due to which, the generated thermal energy dissipates quickly resulting less amount of material melting. Results also show that thickness of white layer depends on pulse current directly. Intensive electric sparks are generated at high pulse current that produce more thermal energy during electric discharge machining.

\section{CONCLUSIONS}

The influence of two electrode materials and two dielectric liquids on low carbon steel $304 \mathrm{~L}$ is studied for different pulse currents. Their effect is investigated in terms of surface conditions like surface morphology, chemical composition and white layer thickness. Generally it was observed that surface cracking is proportional to the amount of carbon contents present in white layer formed after electric discharge machining. The white layer is most enriched with carbon contents when graphite electrode is used in combination with kerosene oil as dielectric liquid, therefore, the surface cracking is highest in this case followed by combination of copper electrode with kerosene than graphite electrode with distilled water. Surface cracking is not seen for the combination of copper electrode with distilled water. Graphite electrode has extreme wear rates, which is highest when used in distilled water and lowest for kerosene oil. An interesting effect of discharge current on EWR of copper electrode in distilled water is seen where contrary to other combinations EWR is decreasing with increasing pulse current. Distilled water offers higher MRR as compared to kerosene where graphite and copper should be respectively preferred for finish and rough machining conditions. The thickness of the white layer is higher in kerosene as compared to distilled water, however, the response of electrode material is different for dielectric liquids. Graphite results higher thickness than copper when machining in kerosene whereas this order is reversed when machining in distilled water. The combination of copper electrode with distilled water for machining at a pulse current higher than $6 \mathrm{~A}$ is suggested for best machining outcome in the form of surface condition, high MRR and decreased TWR. 


\section{REFERENCES}

[1] K. H. Ho, S. T. Newman, "State of the art electrical discharge machining (EDM)", International Journal of Machine Tools and Manufacture, Vol. 43, No. 13, pp. 1287-1300, 2003

[2] S. Mehmood, M. Shah, R. A. Pasha, S. Khushnood, A. Sultan, "Influence of electric discharge machining on fatigue limit of high strength aluminum alloy under finish machining", Journal of the Chinese Institute of Engineers, Vol. 40, No. 2, pp. 118-125, 2017

[3] S. Mehmood, R. A. Pasha, A. Sultan, "Effect of electric discharge machining on material removal rate and white layer composition", Mehran University Research Journal of Engineering \& Technology Vol. 36, No. 1, pp. 45-54, 2015

[4] C. H. Che Haron, J. A. Ghani, Y. Burhanuddin, Y. K. Seong, C. Y. Swee, "Copper and graphite electrodes performance in electricaldischarge machining of XW42 tool steel", Journal of Materials Processing Technology, Vol. 201, No. 1-3, pp. 570-573, 2008

[5] Y. H. Jeong, B. K. Min, "Geometry prediction of EDM-drilled holes and tool electrode shapes of micro-EDM process using simulation", International Journal of Machine Tools and Manufacture, Vol. 47, No. 12-13, pp. 1817-1826, 2007

[6] M. Sohani, V. Gaitonde, B. Siddeswarappa, A. Deshpande, "Investigations into the effect of tool shapes with size factor consideration in sink electrical discharge machining (EDM) process", The International Journal of Advanced Manufacturing Technology, Vol. 45, No. 11-12, pp. 1131-1145, 2009

[7] N. Pellicer, J. Ciurana, T. Ozel, "Influence of process parameters and electrode geometry on feature micro-accuracy in electro discharge machining of tool steel", Materials and Manufacturing processes, Vol. 24, No. 12, pp. 1282-1289, 2009

[8] A. G. Jaharah, C. G. Liang, S. Z. Wahid, M. N. Ab Rahman, C. H. Che Hassan, "Performance of copper electrode in electical discharge machining (EDM) of aisi h13 harden steel", International Journal of Mechanical and Materials Engineering Vol. 3, No. 1, pp. 25-29, 2008

[9] B. Bhattacharyya, S. Gangopadhyay, B. R. Sarkar, "Modelling and analysis of EDMED job surface integrity", Journal of Materials Processing Technology, Vol. 189, No. 1-3, pp. 169-177, 2007

[10] A. A. Khan, "Electrode wear and material removal rate during EDM of aluminum and mild steel using copper and brass electrodes", The International Journal of Advanced Manufacturing Technology, Vol. 39, No. 5-6, pp. 482-487, 2007

[11] F. L. Amorim, W. L. Weingaertner, "The behavior of graphite and copper electrodes on the finish die-sinking electrical discharge machining (EDM) of AISI P20 tool steel", Journal of the Brazilian Society of Mechanical Sciences and Engineering, Vol. 29, No. 4, pp. 366-371, 2007

[12] S. Chakraborty, V. Dey, S. K. Ghosh, "A review on the use of dielectric fluids and their effects in electrical discharge machining characteristics", Precision Engineering Vol. 40, pp.1-6, 2015

[13] Y. Zhang, Y. Liu, R. Ji, B. Cai, "Study of the recast layer of a surface machined by sinking electrical discharge machining using water-in-oil emulsion as dielectric", Applied Surface Science, Vol. 257, No. 14, pp. 5989-5997, 2011

[14] B. Ekmekci, O. Elkoca, A. Erman Tekkaya, A. Erden, "Residual stress state and hardness depth in electric discharge machining: de-ionized water as dielectric liquid", Machining Science and Technology, Vol. 9, No. 1, pp. 39-61, 2005

[15] S. Mehmood, A. Sultan, N. A. Anjum, W. Anwar, Z. Butt, "Determination of residual stress distribution in high strength aluminum alloy after EDM", Advances in Science and Technology Research, Vol. 11, No. 1, pp. 29-35, 2017

[16] F. N. Leão, I. R. Pashby, "A review on the use of environmentallyfriendly dielectric fluids in electrical discharge machining", Journal of Materials Processing Technology, Vol. 149, No. 1-3, pp. 341-346, 2004

[17] S. Chen, B. Yan, F. Huang, "Influence of kerosene and distilled water as dielectrics on the electric discharge machining characteristics of $\mathrm{Ti}$ 6A1-4V", Journal of Materials Processing Technology, Vol. 87, No. 1, pp. $107-111,1999$
[18] P. Sharma, S. Singh, D. R. Mishra, "Electrical discharge machining of AISI 329 stainless steel using copper and brass rotary tubular electrode", Procedia Materials Science, Vol. 5, pp. 1771-1780, 2014

[19] B. Ekmekci, "Residual stresses and white layer in electric discharge machining (EDM)", Applied Surface Science, Vol. 253, No. 23, pp. 9234-9240, 2007

[20] A Descoeudres, Characterization of electrical discharge machining plasmas, Fedral Institute of Technology, Lausanne, Switzerland, 2006 